\title{
Small languages and small language communities 62
}

Editor: Nancy C. Dorian

\author{
REVITALIZATION IN A SCATTERED LANGUAGE \\ COMMUNITY: PROBLEMS AND METHODS FROM THE \\ PERSPECTIVE OF MUTSUN LANGUAGE REVITALIZATION* \\ NATASHA WARNER, QUIRINA LUNA, LYNNIKA BUTLER, \\ and HEATHER VAN VOLKINBURG
}

\section{Abstract}

This article addresses revitalization of a dormant language whose prospective speakers live in scattered geographical areas. In comparison to increasing the usage of an endangered language, revitalizing a dormant language (one with no living speakers) requires different methods to gain knowledge of the language. Language teaching for a dormant language with a scattered community presents different problems from other teaching situations. In this article, we discuss the types of tasks that must be accomplished for dormant-language revitalization, with particular focus on development of teaching materials. We also address the role of computer technologies, arguing that each use of technology should be evaluated for how effectively it increases fluency. We discuss methods for achieving semi-fluency for the first new speakers of a dormant language, and for spreading the language through the community.

\section{Introduction}

The problems of how to increase the usage of an endangered language are well known (e.g., Fishman 2001a). The most extreme case of language revitalization is reversal of a completed language shift, that is, revitalization of a language with no living speakers: a dormant language. In this article, we discuss methods and problems of revitalizing Mutsun, a dormant language of coastal California.

We discuss revitalization particularly for what we refer to as "scattered" communities. Mutsun (Southern Costanoan) was spoken near the San Juan Bautista Mission, south of San Francisco. Mutsun rapidly became endangered after the arrival of the missions, and the last known fluent speaker, Mrs. Ascensión Solórsano, died in 1930. The Mutsun tribe now has no reservation or tribally owned land, and there is no modern 
town in which the Mutsuns are well known as being the original local people, or in which Mutsuns constitute a majority. The approximately 2000 Mutsun people are scattered, with concentrations across a large expanse of California. Hinton (2003) classifies endangered languages by the geographical unit with which they are associated: a country (e.g., Irish, Maori), a state (Hawai'ian), or a village or reservation (e.g., the Pueblo languages). Finally, some languages, like Mutsun, lack any geographic area in which they are now widely recognized, and their community members live in scattered locations. We follow Hinton (2001c) in calling these "scattered languages." 1

Although there are no living speakers, there is surprisingly extensive written documentation of Mutsun (Warner et al. 2006). The largest source is several thousand pages of unpublished, unanalyzed field notes taken by linguist J. P. Harrington during fieldwork with Mrs. Solórsano in 1922 and from 1929 until her death in 1930. Some Mutsuns, including the second author, had a strong desire to reconnect with their heritage language and culture, but they were wrongly told that there was no material on Mutsun. In 1996, they gained access to some of the materials and began learning their heritage language. This initial work with the archival materials was both daunting in the difficulty of the task, and emotionally deeply rewarding.

Several linguists have since joined the community in revitalization work, and we have created a dictionary, a draft language textbook, freestanding language-teaching materials, and a database that contains all recorded information about the Mutsun language (Warner et al. 2007). Furthermore, the authors can hold basic conversations in Mutsun. The first author (a linguist) joined the project as a student mentor at the Breath of Life workshop in 1997 (Hinton 2001b), and then continued work with Mutsun first in her spare time, then as a research program. The third and fourth authors and other students joined the project through either grant-funded or independent-study work supervised by the first author. The Mutsun project is now at a similar stage to the Kaurna dormant-language revitalization project in Australia (Amery 2000). In this article, we discuss the types of work that have been involved in the Mutsun project, methods we have tried, and problems we have encountered.

\section{Tasks in revitalization}

The types of work we have found necessary in the Mutsun languagerevitalization project are wide-ranging. The first step was to determine 
what documentation of the language was available, locate copies, and learn the transcription systems of all sources (tasks discussed for dormant languages generally in Hinton [2001a]). We also developed a practical orthography for Mutsun early in the project, although it has been revised several times at the instigation of community language learners. We developed a lexical database, and eventually a sentence-level text database, to encode and analyze all known data for the language and generate a dictionary (Warner et al. 2006). We have also developed languageteaching materials throughout the duration of the project. The Mutsun project involves cultural revitalization along with language revitalization (Hinton 2001c), so information about cultural practices, songs, traditional plants, etc., must also be extracted from early records or learned from culturally related tribes.

For any dormant-language revitalization project, at least one person must gain modest fluency in the language in order to teach it to others (Hinton 2001a). A further step is to spread language and cultural knowledge through the community. This may involve organizing summer camps, developing strategies to keep learners from switching to the dominant language, and involving a broad group of community members. One must also locate funding or volunteers. A thorough language and culture revitalization project can require a very large team effort, and require the help of people with skills in diverse areas: linguistics, music, illustration, pedagogy, grant writing, and event planning. However, this does not mean that all of these types of work must be accomplished at once, or by any one project. The Mutsun project has done at least some work in all of these areas, but we have not been able to pursue all parts of the work intensively. Approximately 10-15 community members have taken some leadership role at some time, and approximately 50 have attended at least one Mutsun language workshop.

\section{Development of teaching materials}

We will discuss teaching materials in more detail. There are special considerations for teaching materials for a scattered community with a dormant language.

\subsection{Relationship between original data and teaching materials}

Because no one working on the project is a fluent Mutsun speaker, it might seem desirable to use original field data that was collected from a 
native speaker as teaching material. Furthermore, working with original source materials can inspire powerful motivation (Hinton 2001b; Lobo 2001) by serving as a direct connection to one's ancestors, who often provided the data. However, the original source material on Mutsun is highly inaccessible for language learning: it consists of unanalyzed field notes on microfilm, in Harrington's poor handwriting, with glosses in California Spanish, and little explanation of grammar or anything else. It represents linguistic elicitation style, consisting of sometimes improbable sentences using a root in various constructions out of context, and does not demonstrate how to hold a conversation. For example, at one point Harrington elicited the forms tonnoyis! 'Go make him dizzy!,' tonnoy nuk! 'Make him dizzy!', tonnohte-k 'He is dizzy', etc. (Harrington 1922, 1929-1930: 41:0201b). The original data contains idiomatic uses of words or suffixes, low-frequency suffixes that would not be taught at a beginner level, and grammatical structures that are not well understood or were not the most common way to express something. To avoid exposing beginning language learners to the full range of variability of the language, we have focused on developing accessible language-learning materials, but we intend to incorporate original data wherever possible.

Development of language-teaching materials for Mutsun has followed two directions: the writing of a textbook, primarily by the linguists with input from community members, and production of a variety of standalone teaching materials, primarily by community members with input from the linguists. The first and second authors began work on a textbook together early in the revitalization process. This textbook was really a list of example sentences illustrating syntax and morphology, with explanation in nontechnical terminology. Not surprisingly, it was of little use in the community. A newer textbook focuses on communicative competence in daily-life situations and introduces grammar through conversations and stories. We attempt to write texts involving traditional activities wherever possible (e.g., making a feather headdress, harvesting traditional plants, etc.), along with texts on topics of modern life. This textbook is still far from ideal, but when completed, it should allow highly motivated community members the great satisfaction of progress toward semi-fluency.

\subsection{Logistics and online access to the textbook}

Although the Mutsun community does hold language or culture workshops, it is difficult for community members to attend because of distance and lack of time. The main concentrations of Mutsun people are up to a 
three-hour drive apart, and most community members must hold at least one job and take care of children. Therefore, in-person language classes are unlikely to spread the language through the community. Languagelearning materials that can be used individually or in small groups, without a fluent teacher, could supplement less-frequent larger community meetings.

We hope to address this problem by using password-protected distancelearning software for audio examples and oral practice (see Warner et al. 2007). Most members of the Mutsun community do have Web access, so online material may be more accessible than physical meetings. We have chosen to use distance-learning software developed by the University of Arizona (Reynaert et al. 2003, www.ole.arizona.edu). This software allows a "teacher" to post text, audio, and video messages, to which "students" can then listen and post audio, text, or video replies. Over time we expect that the student and teacher roles will merge, with linguists and community members advancing their competence in the language together. ${ }^{2}$ We have also experimented with CD and DVD materials. Eventually, advanced community language learners rather than linguists should serve as the voices for audio materials.

Another strategy for teaching despite the scatter problem is to form a small group of highly dedicated language learners, including at least one from each geographical area, who will then become teachers for the communities they live in. The Mutsun community has founded such a language committee, consisting of six to eight adults committed to dedicating a large amount of time to language work. However, in a scattered community, even a language committee may not be able to meet very often.

\subsection{Stand-alone teaching materials}

We, particularly the second author, have also created many independent teaching materials, including games, songs, flashcards, etc. These are often based on games familiar to community members from the broader American culture. Some examples are a Mutsun version of Twister (for learning colors and body parts), Mutsun Hokey-Pokey (body parts, some imperatives), a matching/memory game that teaches which plural allomorph to use in which environment, Mutsun Go Fish, Mutsun Blackjack (for higher numbers), Coyote Says (based on Simon Says, for imperatives), etc.

Many of these activities are effective for getting community members involved in language learning and for teaching particular lexical areas. The blackjack game is a prime example: the numbers above 10 in Mutsun (shown in Example [1]) are attested (Arroyo 1861: 16), but they are long 
and difficult. We considered creating shorter forms, reasoning that the numerals would have undergone elision had the language not become dormant. However, the attested forms quickly became easier with practice. The blackjack game supplies ample practice, and community members who play it become very fluent with higher numbers. If language revitalization succeeds and these long numbers come into common use, they may undergo shortening, but as a natural part of language change.

(1) tansakte hemec'a-k iccos

$10 \quad 1-3$ rd sub. come out-rem. past

'11' (lit. '10-1 it came out')

kaphan tansakte parwes-ak iccos

$3 \quad 10 \quad 5-3$ rd sub. come out-rem. past

' 35 ' (lit. ' $3-10-5$ it came out')

We have also developed language for a traditional game in Mutsun. Harrington documented how the traditional stick game Tallik was played, along with lexical items specific to the game (the names of the throwing sticks, the score-keeping sticks, and the game itself). Using this information from Harrington and general knowledge of Mutsun, we made a list of phrases for this game, so that children and adults can play a traditional game while speaking entirely in Mutsun.

We have also developed longer texts. Community members translated Dr. Seuss's children's story Green Eggs and Ham into Mutsun (cutsuSmin moTe yии tooTe 'blue/green-one egg and meat') in 2000 at a Breath of Life language-revitalization workshop (Hinton 2001b; Luna-Costillas et al. 2002). This early-reader text is an excellent choice for language learning because it is highly repetitious. A version converted to traditional culture ("Green acorns and salmon") is planned. We have also translated a traditional Mutsun story (the story of the thunders), which was written only in English and Spanish, back into Mutsun. We know of only part of one traditional story, the story of One-leg, that was ever written down in Mutsun, but we have translated the remainder of that story back into Mutsun as well. At a community language workshop, having children act out the story of One-leg while it was narrated in Mutsun was very popular. The continuing development of longer stories on both traditional and modern concepts diversifies the repertoire of language-learning materials.

\section{Technology and language revitalization}

Computer technology for endangered languages has received considerable attention recently (e.g., Hinton and Hale 2001, part VII; and the Indige- 
nous Languages and Technology listserv, http://projects.ltc.arizona.edu/ gates/ilat.html). We have adopted some technologies for the Mutsun language revitalization process, but we emphasize evaluating just what return the community receives in increased fluency from the investment of time, energy, and money in a particular technology.

We make extensive use of databases, currently SIL's FieldWorks Language Explorer (SIL 2006), for the analysis of original source data for Mutsun and for producing the dictionary (see discussion in Warner et al. 2006). For language teaching, we plan to use technology primarily by providing oral practice through the online distance-learning software. In this scattered community, the use of technology has the potential for a great return in fluency because of geographical distance and the community's access to the Web. The particular distance-learning software we have chosen is already available and is easy to learn, so this technology requires limited investment of effort.

We have made only a little use of technology for other teaching materials, and we have not developed Mutsun audiovisual language-lesson CDs, for example. Such methods often focus on memorization of lexical items (e.g., by having learners click on a picture to hear a recording of the word). This does not create fluent speakers, and requires substantial effort to produce.

We are in the process of developing a Mutsun spellchecker for use in a word-processing program, because a programmer volunteered to develop this. This technology is especially useful for a dormant language: with analysis of the source materials ongoing, we have to learn new forms of words as better information becomes available. If a learner has memorized 'to buy/sell' as upu (attested in Mason [1916], analyzed early in the project), and it is later changed to huиpu (the Harrington form, analyzed later), the learner would be corrected by the spellchecker. We hope to include a function in the spellchecker program that will check whether a form is a variant from an alternative source (Warner et al. 2006) and suggest the main form for it.

\section{Problems encountered in Mutsun language revitalization, and tentative solutions}

\subsection{Developing the first semi-fluent speakers}

Learning to speak a language that has no living speakers at all is almost, but not completely, unprecedented. Daryl Baldwin of the Miami Tribe taught himself to speak his ancestral language, Myaamia, from archival 
sources (Hinton 2001a; Leonard 2004), just as the Mutsuns are attempting to do. He is now raising his four children largely in Myaamia (Leonard 2004). Cornish developed first speakers longer ago (George and Broderick 2002). There are also cases of first speakers of constructed languages, such as Esperanto and Star Trek's Klingon. ${ }^{3}$ Although learning of constructed languages differs in the relationship of the community to the language and in how gaps in language competence are filled, the process of creating the first semi-fluent speakers is similar. The revitalization of Hebrew (Kutscher 1982; Sáenz-Badillos 1993; Hinton 2001a), however, is different, since Hebrew was still being used at least for religious purposes when the development of Modern Hebrew began.

Our primary methods for gaining semi-fluency in Mutsun are learning the syntax from the Okrand (1977) grammar, learning lexical items from the dictionary we have been developing, writing (by e-mail) in Mutsun, and practicing speaking in Mutsun with each other. The second author also uses Mutsun with her four children whenever possible, but this is currently mostly confined to single words and set phrases. At this point, the first three authors can hold simple conversations about daily-life topics or tell simple stories entirely in Mutsun, without rehearsing the material in advance. During in-person visits, the first two authors have attempted to speak only Mutsun with each other whenever possible. We were able to talk in Mutsun $20-30 \%$ of the time, and we found this progress extremely satisfying. With practice, we expect that Mutsun conversation will become easier.

When one receives no language input, making the jump from memorizing set phrases or laboriously constructing sentences morpheme-bymorpheme to generating language productively is very difficult. One strategy we have found helpful is to spend time several days per week writing simple conversations and stories in Mutsun, since writing does not require one to generate sentences as quickly as speaking. These stories can be used as material for the textbook later. At least for the first author (who is a linguist), frequent practice writing on simple topics in Mutsun has led to an increase in ability to speak at nearly conversational speed.

Another helpful strategy is talking to babies in the language, whether the goal is to raise the child in the language or not. Conversations with young children are easier to confine to basic syntax and vocabulary, and pre-linguistic children are a cooperative audience. ${ }^{4}$ When adults begin learning their ancestral language, they often want to say complex and poetic things, perhaps expressing their feelings about language loss and revitalization. Even typical conversations among adults quickly founder on multi-clause sentences and abstract or specialized lexical items. Conversations with a small child may be more manageable. Clearly, adults also 
need to learn to have simpler adult-directed conversations, but addressing children may be a good stepping stone to semi-fluency.

To make the jump to semi-fluency, Hinton et al. (2002) suggest that one could speak the target language even to (presumably patient) adults who are not learning it, and then repeat in English, in order to get enough practice speaking. Working with the dormant language Kaurna, Amery (2000, 2001) suggests a "formulaic method" of introducing memorized phrases. Regardless of the method used, creating even a few initial semifluent speakers is a prerequisite to solving all other problems. Making the jump to semi-fluency without spoken input is extremely difficult, and it is easy to underestimate this task in the revitalization process.

\subsection{Problems in language teaching}

Beyond the issues of teaching materials discussed above, dormantlanguage revitalization creates an extremely difficult language-teaching situation. The teacher will not be a fluent speaker. When Mutsun community language classes are held, the attendees vary greatly in age (1-60+), past experience with Mutsun (from first-time attendees to people who come to every class), motivation (from people trying out the class to revitalization leaders), and amount of formal education. Most community members are monolingual English speakers and have never had the experience of learning to converse fluently in a second language. Classes are held infrequently because of the scattered language situation. Finally, ongoing analysis of the original source materials leads to changes in what is considered grammatical.

For most community members, teaching using games and immersion methods, rather than analytical language-learning, is preferable (cf. Lobo 2001). We are not currently able to provide a true immersion environment, although we attempt to use Mutsun wherever possible in language teaching (by greeting workshop participants at the door in Mutsun, writing nametags in Mutsun orthography, narrating stories only in Mutsun and acting them out rather than translating, etc.). We use a large proportion of games and songs in language teaching, integrating a little grammar. Still, separate activities for children and adults have been necessary, and finding activities that are engaging for all ages and activity levels of children is challenging.

One thing that favors Mutsun revitalization is that the language has simple syllable structure, transparently agglutinating suffixal morphology, and only a few phonemes the dominant language (English) lacks. Phonological simplicity certainly facilitates teaching under difficult 
dormant-language circumstances. Dormant-language revitalization would be far harder for an Athapaskan language, for example.

\subsection{Beyond the classroom}

In revitalization work, as with endangered languages, it is important to consider which efforts are likely to create semi-fluent speakers and which are not. Language lessons taught in a classroom, even under the best circumstances, are not as likely to produce fluency as immersion during reallife activities. (See Dulay et al. [1982: ch. 2] for discussion of the impact of natural language input, Hinton [1997] on learning languages in a dailylife environment, and Fishman [2001b] and Hinton [2001c] on the inefficacy of entirely school-based language learning.) This is even truer for a scattered community. Although language games and activities are useful, these are also unlikely to create fluent speakers. Similarly, no use of modern technology will create fluency without sufficient input and opportunities for interaction.

The only way for children and most adults to achieve even semi-fluency is through immersion, in a situation where everyone around the learner insists on speaking only the target language. We invite readers to consider how they reached fluency in any L2 in which they can converse somewhat comfortably. For us, this has been either through immediate immersion in the society where the language is spoken or through analytical classroom study followed by immersion during study-abroad. Whatever basis formal language study may provide, spending many hours interacting in the L2 is what leads to fluency.

We are not currently able to provide a good immersion environment in Mutsun, even with one speaker, let alone a society. However, a crucial difference between revitalization and L2-learning of a non-ancestral language is in motivation. The revitalization leaders in the Mutsun community are tremendously motivated by the need for cultural identity and connection with the ancestors whose language was destroyed. This makes it possible that a small number of adults might gain semi-fluency from less-than-ideal teaching materials, and then spread their knowledge through the community by becoming the source of immersion input for other learners, while simultaneously increasing their own fluency.

It is important to train Mutsun community members in how and why to stay in the target language even though none of their interlocutors are fluent speakers. Switching to a dominant language when communication becomes difficult reinforces the idea that the dominant language is the "real" means of communication, while use of the target language is a 
sort of game. Using only the target language reinforces the feeling that the language is truly for communication (Hinton 1997; Pecos and BlumMartinez 2001). When two speakers have a common language in which both are fluent (such as English), the temptation to switch to that language because it will be readily understood is very strong (Romero 2003; Pecos and Blum-Martinez 2001). A technique for staying in the target language can be as simple as saying oySo 'again' instead of "what?". However, learning an L2 by immersion seems to be very hard work at first even under good circumstances (for example, study-abroad in a monolingual host family after a few years of classroom study). We remember the early stages of our own L2 immersion experiences as being overwhelmingly difficult. Only the most motivated of learners would persevere and stay in an immersion setting in a dormant language.

In the medium to long term, we hope that semi-fluent Mutsun speakers will be able to offer summer language-immersion camps, possibly similar to those developed at Cochiti Pueblo and used very effectively there (Pecos and Blum-Martinez 2001). Perhaps even an immersion daycare will eventually become possible. Once a few semi-fluent speakers exist, methods used for severely endangered languages can be applied. Fishman (2001b) argues that these situations are really the same. Even the masterapprentice program (Hinton 1997) might work as a means of bringing a few more speakers to the semi-fluent stage quickly. Mutsun revitalization leaders attend conferences on endangered languages in order to find out what works to produce fluent speakers in other communities.

\section{Conclusions}

The difficulties of increasing use even of an endangered language may seem insurmountable, since so few communities are definitively succeeding at reversing language shift. In comparison, the task of revitalizing a dormant language such as Mutsun seems all the more daunting. Dormant-language revitalization requires demanding work beyond what is usually necessary for an endangered language: extracting language information from archival sources, compiling across sources, and achieving semi-fluency for a few speakers. The situation then becomes much like an endangered language situation, and how to spread semi-fluency throughout the community becomes an issue. If the language is also a "scattered language," lacking a cohesive area in which the community members predominate, the problems might feel overwhelming.

We do not know at this point how likely it is that a scattered, dormant language can be successfully revitalized. The optimistic long-term goal for 
Mutsun would be a self-sustaining community of Mutsun-English bilinguals, with Mutsun used among community members and English used in the broader society. Whether that goal can be achieved or not, Mutsun community members already have far more access to their heritage language and culture now than they did when the revitalization project began (Warner et al. 2007). Moreover, it is the belief of the authors that Mutsun revitalization can progress much further. We look forward to finding out just how far this revitalization process can go in the upcoming years.

\section{Department of Linguistics, University of Arizona/ Max Planck Institute for Psycholinguistics, Nijmegen Amah Mutsun Tribal Band}

Correspondence address: nwarner@u.arizona.edu

\section{Notes}

* We wish to acknowledge support for this project from the National Endowment for the Humanities (grant PA-51356-05), the Woodrow Wilson Foundation, the Seventh Generation Fund, and the Native Cultures Fund. We have benefited from discussion of these issues with Leanne Hinton, Wes Leonard, Daryl Baldwin, Mary Willie, Ben Tucker, Juliette Blevins, and participants at the Breath of Life workshops. Any errors or misunderstandings are, of course, our own.

1. Hinton (2001c: 6) uses the phrase "scattered community," but not as an explicit term.

2. The "student" and "teacher" roles are imposed by the software, which was developed for more traditional course use. Otherwise we would not use this terminology.

3. Klingon has an indirect tie to Mutsun: Marc Okrand, the author of the Mutsun grammar, was the developer/author of Klingon. A small number of devoted, highly motivated Star Trek fans have become relatively fluent Klingon speakers, and they are undertaking various efforts to increase the use of Klingon (www.kli.org).

4. The first author began speaking Mutsun by naming an object in Mutsun to her prelinguistic son, then gradually making the utterance more complex. An example in translation, spoken while her son played with rocks, might be "Rock. Rocks. Many rocks. You have many rocks. Pretty rocks. You have many pretty rocks. Look at the pretty rocks. Don't eat the rock!" This child is not being raised in Mutsun, and the purpose was solely practice for the adult.

\section{References}

Amery, Rob. 2000. Warrrabarna Kaurna! Reclaiming an Australian language. Lisse: Swets and Zeitlinger.

Amery, Rob. 2001. Language planning and language revival. Current Issues in Language Planning 2. 141-221. 
Arroyo de la Cuesta, Felipe. 1861. Grammar of the Mutsun language, spoken at the Mission of San Juan Bautista, Alta California (Shea's Library of American Linguistics 4). New York: Cramoisy Press. (Reprinted 1970 by AMS Press, New York, and subsequently by Coyote Press, Salinas, CA.)

Dulay, Heidi, Marina Burt \& Stephen Krashen. 1982. Language two. Oxford: Oxford University Press.

Fishman, Joshua. 2001a. Why is it so hard to save a threatened language? (A perspective on the cases that follow). In J. Fishman (ed.), Can threatened languages be saved? Reversing language shift, revisited: A 21st century perspective, 1-22. Clevedon: Multilingual Matters.

Fishman, Joshua. 2001b. If threatened languages can be saved, then can dead languages be revived? Current Issues in Language Planning 2. 222-230.

George, Ken \& George Broderick. 2002. The revived languages: Modern Cornish and Modern Manx. In M. Ball and J. Fife (eds.), The Celtic languages, 644-663. London: Routledge.

Harrington, John Peabody. 1922, 1929-1930. The papers of John Peabody Harrington in the Smithsonian Institution. Microfilm volume II, reels 37-61.

Hinton, Leanne. 1997. Survival of endangered languages: The California master-apprentice program. International Journal of the Sociology of Language 123. 177-191.

Hinton, Leanne. 2001a. Sleeping languages: Can they be awakened? In L. Hinton \& K. Hale (eds.), The green book of language revitalization in practice, 413-417. San Diego, CA: Academic Press.

Hinton, Leanne. 2001b. The use of linguistic archives in language revitalization: The Native California Language Restoration Workshop. In L. Hinton \& K. Hale (eds.), The green book of language revitalization in practice, 419-423. San Diego, CA: Academic Press.

Hinton, Leanne. 2001c. Language revitalization: An overview. In L. Hinton \& K. Hale (eds.), The green book of language revitalization in practice, 3-18. San Diego, CA: Academic Press.

Hinton, Leanne. 2003. Language revitalization. Annual Review of Applied Linguistics 23. $44-57$.

Hinton, Leanne \& Kenneth Hale. 2001. The green book of language revitalization in practice. San Diego, CA: Academic Press.

Hinton, Leanne, Matt Vera, Nancy Steele \& AICLS. 2002. How to keep your language alive: A commonsense approach to one-on-one language learning. Berkeley: Heyday Books.

Kutscher, Eduard Yechezkel. 1982. A history of the Hebrew language, Raphael Kutscher (ed.). Jerusalem: The Magnes Press, The Hebrew University.

Leonard, Wesley. 2004. The acquisition of Miami: Findings from a field study. Paper presented at the 36th Annual Algonquian Conference, Madison, WI.

Lobo, Kelina. 2001. Bringing a "dead" language back to life: Beginning language instruction for dormant languages. Berkeley, CA: University of California Master's thesis.

Luna-Costillas, Quirina, Monica Luna, Genevieve Luna \& Natasha Warner (trans.). 2002. Tcutsus Ymin motRese yuu tootRese [Green Eggs and Ham, by Dr. Seuss]. Unpublished manuscript.

Mason, J. Alden. 1916. The Mutsun dialect of Costanoan based on the vocabulary of De La Cuesta. University of California Publications in American Archaeology and Ethnology 11(7). 399-472.

Okrand, Marc. 1977. Mutsun grammar. Berkeley, CA: University of California Ph.D. dissertation.

Pecos, Regis \& Rebecca Blum-Martinez. 2001. The key to cultural survival: Language planning and revitalization in the Pueblo de Cochiti. In L. Hinton \& K. Hale (eds.), The green book of language revitalization in practice, 75-85. San Diego, CA: Academic Press. 


\section{$148 \quad$ N. Warner et al.}

Reynaert, Jim, Susan Penfield \& Garry Forger. 2003. An online language lab: Reaching and teaching at a distance. Talk presented at Elearn 2003, Phoenix, AZ, 7-11 November.

Romero, Mary Eunice. 2003. Perpetuating the Cochiti way of life: A study of child socialization and language shift in a Pueblo community. Berkeley, CA: University of California $\mathrm{PhD}$ dissertation.

Sáenz-Badillos, Angel. 1993. A history of the Hebrew language, John Elwolde (trans.). Cambridge: Cambridge University Press.

SIL (Summer Institute of Linguistics). 2006. SIL FieldWorks Language Explorer. http:// www.sil.org/.

Warner, Natasha, Lynnika Butler \& Quirina Luna-Costillas. 2006. Making a dictionary for community use in language revitalization: The case of Mutsun. International Journal of Lexicography 19. 257-285.

Warner, Natasha, Quirina Luna \& Lynnika Butler. 2007. Ethics and revitalization of dormant languages: The Mutsun language. Language Documentation and Conservation 1. $58-76$. 